\title{
Prediction of Birth Weight by Using Neonatal Anthropometric Parameters at Birth in Finote Selam Hospital, Ethiopia
}

\section{Chalachew Tiruneh (D) \\ Daniel Teshome (D)}

Department of Anatomy, College of Medicine and Health Science, Wollo University, Dessie, Ethiopia
Correspondence: Chalachew Tiruneh Tel +251920245474

Email Chalachewtiruneh19@gmail.com
Introduction: Birth weight is an indicator of a newborn's chances for survival and growth. However, developing countries lack enough weighing scales to identify low birth weight babies. Therefore, finding an alternative to weighing scales is vital.

Objective: To predict birth weight from neonatal anthropometric parameters at birth in Finote Selam Hospital, Ethiopia.

Methods: A hospital-based cross-sectional study was carried out from July 13 to October 27, 2020. A total of 424 live-delivered neonates were enrolled. Based on eligibility, birth weight and neonatal anthropometric parameters like crown-heel length, foot length, hand length, mid-upper arm circumference, umbilical-nipple distance, intermammary distance and head circumference were measured within 24 hours of birth. The association between birth weight and neonatal anthropometric parameters was evaluated using correlation analysis. Birth weight predictive regression models were formulated by using simple and multiple linear regression analysis.

Results: All neonatal anthropometric parameters had positive significant correlation with birth weight at $p<0.05$. Amongst the neonatal anthropometric parameters, the highest significant correlation with birth weight was observed on mid-upper arm circumference (MUAC) followed by foot length (FL), each being $r=0.474$ and $r=0.461$, respectively. The best predictive regression models were formulated as birth weight $(\mathrm{kg})=0.117+[0.284 \times \mathrm{MUAC}(\mathrm{cm})]$ and birth weight $(\mathrm{kg})$ $=1.137+[0.254 \times \mathrm{FL}(\mathrm{cm})]$. As compared to individual neonatal anthropometric parameters, a combination of MUAC, hand length (HL), FL and crown-heel length (CHL) had the highest significant correlation ( $r=0.661)$, and a multiple regression equation used to estimate birth weight was formulated as birth weight $(\mathrm{kg})=-2.489+[0.192 \times \mathrm{MUAC}(\mathrm{cm})]+[0.078 \times \mathrm{HL}(\mathrm{cm})]+[0.11 \times \mathrm{FL}$ $(\mathrm{cm})]+[0.036 \times \mathrm{CHL}(\mathrm{cm})]$.

Conclusion: Using a combination of MUAC, HL, FL and CHL followed by individual MUAC neonatal anthropometric parameters has high significance to identify low birth weight. Prediction of neonatal birth weight from neonatal anthropometric parameters is crucial to minimize the death of neonates due to low birth weight.

Keywords: prediction, birth weight, neonatal parameters, Finote Selam Hospital

\section{Introduction}

Globally, child mortality has decreased dramatically in the $20^{\text {th }}$ century. ${ }^{1}$ However, the neonatal mortality reduction rate has been slow, and neonatal mortality still contributes almost half $(41.6 \%)$ of all under-5 mortality. ${ }^{2}$ Low birth weight (LBW, $<2500 \mathrm{~g}$ ), which accounts for about one-sixth of all newborns, is one of the main risk factors for neonatal death. ${ }^{3}$ So, early identification of birth weight using 
neonatal parameters as an alternative to weighing scales is crucial to decrease neonatal death due to LBW in resourcelimited countries.

Birth weight is an indicator of a newborn's chances for survival, growth, long-term health and psychosocial development. ${ }^{4}$ According to the World Health Organization (WHO), neonates with birth weights of less than $2500 \mathrm{~g}$ are considered as low birth weight (LBW) irrespective of gestational age. The LBW subdivisions include very low birth weight, which is less than $1500 \mathrm{~g}$, and extremely low birth weight, which is less than 1000 g. ${ }^{5}$ Identifying neonates with birth weight less than 2500 $\mathrm{g}$ is critical since below this value infant mortality begin to rise rapidly. ${ }^{6}$ Therefore, LBW is considered to be associated with a greater risk of early childhood death than is associated with normal birth weight. ${ }^{7}$

According to the WHO, the global prevalence of LBW is $15.5 \%$, which accounts for about 20.6 million LBW infants born each year, $96.5 \%$ of them in developing countries. ${ }^{8}$ Ethiopia is one of the developing countries which have a higher burden of LBW. The WHO country cooperation strategy 2008-2011 revealed that the prevalence of LBW in Ethiopia was estimated to be $14 \%{ }^{9}$ Hence, LBW is one of the principal causes of perinatal deaths and remains a worldwide issue and one of the most important public health problems, particularly in developing countries. ${ }^{10}$

The risk of death increases as the birth weight is lower. Neonates born with a weight between 2000 and $2499 \mathrm{~g}$ are 4 times more likely to die during their first 28 days of life than neonates born with a weight between 2500 and 2999 $\mathrm{g}$, and 10 times more likely to die than those weighing 3000-3499 g. ${ }^{11}$

A weighing scale is the appropriate, accurate and standard equipment for the identification of birth weight. ${ }^{12}$ However, developing countries like Ethiopia lack enough weighing scales to identify low birth weight for every child. $^{13}$ In addition, most of the women in developing countries deliver in their home, and the birth is attended by traditional birth attendants. Considering this problem, there is a need of alternative methods to identify birth weight from neonatal anthropometric parameters. Anthropometric measurements are easy to perform and manage. Therefore, finding an alternative method which is simple to use, quick and involving low-cost instruments is vital, especially in low-resource settings, so that low birth weight can be identified at the community level and referred to higher health care settings for further management. In Ethiopia, there are health extension workers who can identify LBW using neonatal anthropometric measurements while they do home visits as the usual dayto-day activities. Thus, this study aimed: 1) to identify the relation between birth weight and neonatal anthropometric parameters like mid-upper arm circumference (MUAC), head circumference (HC), hand length (HL), foot length (FL), intermammary distance (IMD), umbilical-nipple distance (UND) and crown-heel length (CHL) at birth; 2) to find the best parameters for prediction of birth weight from these neonatal anthropometric measurements alone or in combination; and 3) to formulate regression models for prediction of birth weight from the above neonatal anthropometric parameters.

\section{Methods and Materials Study Setting and Period}

This hospital-based prospective cross-sectional study was conducted from July 13 to October 27, 2020, at Finote Selam hospital, Ethiopia. The study was carried out in the Obstetrics and Gynecology unit. The hospital is located in Finote Selam town. Finote Selam, the "Pacific Road", is the name given by Emperor Haile Selassie during the Italian attack on Ethiopia. Formerly its name was Wojet. Now the town is the capital city of West Gojjam. The town is located $387 \mathrm{~km}$ from Addis Ababa, the capital city of Ethiopia, and $176 \mathrm{~km}$ from Bahir Dar, the capital city of Amhara regional state.

The town has only one hospital, Finote Selam hospital, which is a district hospital that has been serving the community for many years. It provides both inpatient and outpatient services. It has four wards, including Obstetrics and Gynecology. Around 250 neonates per month are delivered at Finote Selam hospital.

\section{Source and Study Population}

All delivered neonates during the study period were the source population, and alive delivered neonates and those who fulfill the inclusion criteria were the study population.

\section{Sample Size Determination and Sampling Techniques}

The minimum required sample size was calculated using a single population proportion formula by considering $p=50 \%, \mathrm{CI}=95 \%$ and $5 \%$ margin of error. Finally, to compensate for non-response rate, $10 \%$ was added. Thus, to conduct this study a sample size of 424 was used. 
Based on the eligibility criteria, a purposive sampling technique was employed to select the samples, and these samples were selected until the necessary samples were obtained.

\section{Eligibility Criterion}

All live-born neonates within 24 hours of life were included in the study,whereas the following groups of neonates were excluded from the study:

- Neonates older than 24 hours

- Twin neonates

- Newborn with severe perinatal asphyxia

- Newborn with gross congenital anomalies

- Neonates born with unknown gestational age (ie mother does not remember the LNMP)

- Neonates who were born from women with the following known chronic maternal diseases: hypertension, diabetes mellitus, cardiac disease and severe anemia, as well as TORCH infection positive mothers

- Neonates born from women with obstetrical complications that are known to compromise fetal growth eclampsia, smoking history, alcohol consumption or drug abuse

\section{Anthropometry Equipment}

- Flexible, non-elastic measuring tape

- Weighing scale

\section{Data Collection Tools and Procedures}

A well-prepared checklist was used to collect the relevant information. The tool was adapted from previously published literature. The tool consists of a consent form, sociodemographic characteristics and neonatal anthropometric measurements like CHL, FL, HL, MUAC, UND, IMD, HC and birth weight (BW).

The medical records were reviewed for different findings, and then neonates were checked by physical examination for their normal appearance. After endorsement of the normal appearance of a newborn by physical examination, the study subjects were enrolled in the study. To measure the different neonatal anatomical parameters, the neonates were in the supine position. The neonatal anthropometric parameters were measured via a non-elastic measuring tape to the nearest 0.1 centimeter $(\mathrm{cm})$, and the birth weight was measured by a balanced neonatal weight scale in kilograms $(\mathrm{kg})$. The gestational age of the study participant was calculated from the history sheets by the use of "Naegele's formula" (i.e. count back 3 months from the first day of the LNMP and then add 1 year plus 7 days). ${ }^{14}$

Mid-upper arm circumference was measured at the midpoint circumference of the humerus between the acromion end of the clavicle and the olecranon process of the ulna. The right side arm was measured. ${ }^{14}$

Foot length was measured with a non-elastic measuring tape as the maximum length between the most prominent posterior point of the heel and the tip of hallux or the tip of the second toe if it was longer than the hallux. ${ }^{15}$ Hand length was measured from the distance between the heel of the hand and the tip of the middle finger. ${ }^{16}$ Both foot length and hand length were measured from the right side of the body.

Head circumference was measured by a non-elastic measuring tape which encircled the head just above the superciliary arch on the anterior aspect, just above the auricle on the lateral aspect, and at the level of external occipital protuberance on the posterior aspect. ${ }^{17}$

Umbilical-nipple distance was measured between the 12 o'clock position of the rim of the umbilicus to the right nipple. ${ }^{16}$ Intermammary distance was measured between the nipples at the end of expiration.

The crown-heel length of the neonate was measured from the highest point on the head in the mid-sagittal plane (vertex) of the skull to the heel of the foot. ${ }^{18}$

\section{Data Quality Control}

The data were collected by two BSc in Midwifery professionals who work in the delivery room. To keep data quality, training on neonatal body measurement and avoiding common errors during measurement was given for the data collectors. The data were collected within 24 hours of delivery. All measurements were taken by the trained personnel. A well-designed data collection material was prepared. Anthropometric parameters were measured by non-stretchable tape and documented to the nearest of $0.1 \mathrm{~cm}$. To keep reproducibility, each measurement was repeated two times, and the average was documented. During the period of data collection, the principal investigators carried out day-to-day supervision. Moreover, the data were checked for consistency and completeness.

\section{Data Processing and Analysis}

Before the data analysis, the data were checked for clarity, completeness and accuracy. Then, it was entered in EPI data version 3.1 and exported to SPSS version 23 for analysis. Data were cleaned and edited before analysis. 
With the assumption of normality, the distribution of data was tested and it was normally distributed. The multicollinearity between the independent variables was assessed using variance inflation factor (VIF), and it was less than ten. The relation between neonatal anthropometric parameters and birth weight was tested using correlational analysis. A statistically significant correlation was set at a $P$-value of less than 0.05 . Simple and multiple linear regression analyses were done. In simple linear regression analysis, a stepwise regression analysis was carried out. To predict birth weight, a linear regression model was formulated from different neonatal anthropometric parameters. The fitness of regression models was assessed using coefficients of determination $\left(r^{2}\right)$ and residual plots. The predictive accuracy of the regression models was also evaluated using the mean absolute error (MAE) and mean average percentage error (MAPE). Finally, the data were presented in text, tables and graphs.

\section{Ethical Considerations}

Ethical clearance was obtained from Wollo University, College of Medicine and Health Science, Department of Preclerkship. A supporting letter was sent to Finote Selam Hospital, and consent was gained from the hospital director to conduct a study. The purpose of the study was explained to each study participant's parent/legal guardians. Verbal informed consent was obtained for participant's parents/legal guardians who could not read and write, and the verbally informed consent process was approved by the DRERC of Wollo University, while written informed consent was gained from each participant's parent/guardians who could read and write. Privacy was kept by taking the data anonymously, and also the participant's parent/guardians had the right to be excluded from the study if they did not want to participate.

\section{Results}

\section{Sociodemographic Characteristics}

In this study, 424 live delivered neonates participated. Among these, more than half, 218 (51.4\%), of the neonates were male, and the majority of the neonates were termdelivered, $343(80.9 \%)$. The birth weights of the newborns were in the range of 2.2 to $4.5 \mathrm{~kg}$, with a mean birth weight of $3.17 \pm 0.41 \mathrm{~kg}$. The mean ages of the neonates' mothers were $26.76 \pm 5.17$ years. More than half, $262(61.8 \%)$, of the mothers came from urban homes. Most of the women were Orthodox religion followers, 327 (77.1\%), followed by Muslim, $50(11.8 \%)$. More than one-third of the neonates'
Table I Sociodemographic Characteristics of Respondents in Finote Selam Hospital, Ethiopia

\begin{tabular}{|c|c|c|c|}
\hline \multicolumn{2}{|l|}{ Variables } & \multirow{2}{*}{$\begin{array}{l}\text { Frequency } \\
35 \\
85 \\
185 \\
98 \\
21\end{array}$} & \multirow{2}{*}{$\begin{array}{l}\text { Percent } \\
8.3 \\
20 \\
43.6 \\
23.1 \\
5\end{array}$} \\
\hline Maternal age & $\begin{array}{l}<20 \\
20-24 \\
25-29 \\
30-35 \\
>35\end{array}$ & & \\
\hline Sex of Neonates & $\begin{array}{l}\text { Male } \\
\text { Female }\end{array}$ & $\begin{array}{l}218 \\
206\end{array}$ & $\begin{array}{l}51.4 \\
48.6\end{array}$ \\
\hline $\begin{array}{l}\text { Status of } \\
\text { newborn }\end{array}$ & $\begin{array}{l}\text { Pre-term }(<37 \\
\text { weeks) } \\
\text { Term }(37-42 \text { weeks })\end{array}$ & $\begin{array}{l}81 \\
343\end{array}$ & $\begin{array}{l}19.1 \\
80.9\end{array}$ \\
\hline $\begin{array}{l}\text { Residence of } \\
\text { mothers }\end{array}$ & $\begin{array}{l}\text { Urban } \\
\text { Rural }\end{array}$ & $\begin{array}{l}262 \\
162\end{array}$ & $\begin{array}{l}61.8 \\
38.2\end{array}$ \\
\hline $\begin{array}{l}\text { Religion of } \\
\text { mothers }\end{array}$ & $\begin{array}{l}\text { Orthodox } \\
\text { Muslim } \\
\text { Protestant } \\
\text { Others }\end{array}$ & $\begin{array}{l}327 \\
50 \\
41 \\
6\end{array}$ & $\begin{array}{l}77.1 \\
11.8 \\
9.7 \\
1.4\end{array}$ \\
\hline $\begin{array}{l}\text { Educational } \\
\text { status of } \\
\text { mothers }\end{array}$ & $\begin{array}{l}\text { Cannot read and } \\
\text { write } \\
\text { Can read and write } \\
\text { Primary school } \\
\text { completed } \\
\text { Secondary school } \\
\text { completed } \\
\text { Higher education }\end{array}$ & $\begin{array}{l}35 \\
19 \\
161 \\
161 \\
48\end{array}$ & $\begin{array}{l}8.3 \\
4.5 \\
38 \\
38 \\
11.3\end{array}$ \\
\hline Occupation & $\begin{array}{l}\text { Not employed } \\
\text { Housewife } \\
\text { Employed in } \\
\text { governmental } \\
\text { institution } \\
\text { Employed in private } \\
\text { sector } \\
\text { Merchant }\end{array}$ & $\begin{array}{l}12 \\
2\end{array}$ & $\begin{array}{l}4.2 \\
85.8 \\
6.6\end{array}$ \\
\hline
\end{tabular}

mothers had completed primary and secondary school, each accounted for 161 (38\%). And also, the majority of women were housewives, $364(85.8 \%)$, followed by governmental institution employed, 28 (6.6\%) (Table 1 and Figure 1).

\section{Estimation of Birth Weight from Neonatal Anthropometric Parameters}

Pearson's correlation coefficient $(R)$ between birth weight and various neonatal anthropometric measurements are presented in Table 2. All of the neonatal anthropometric 


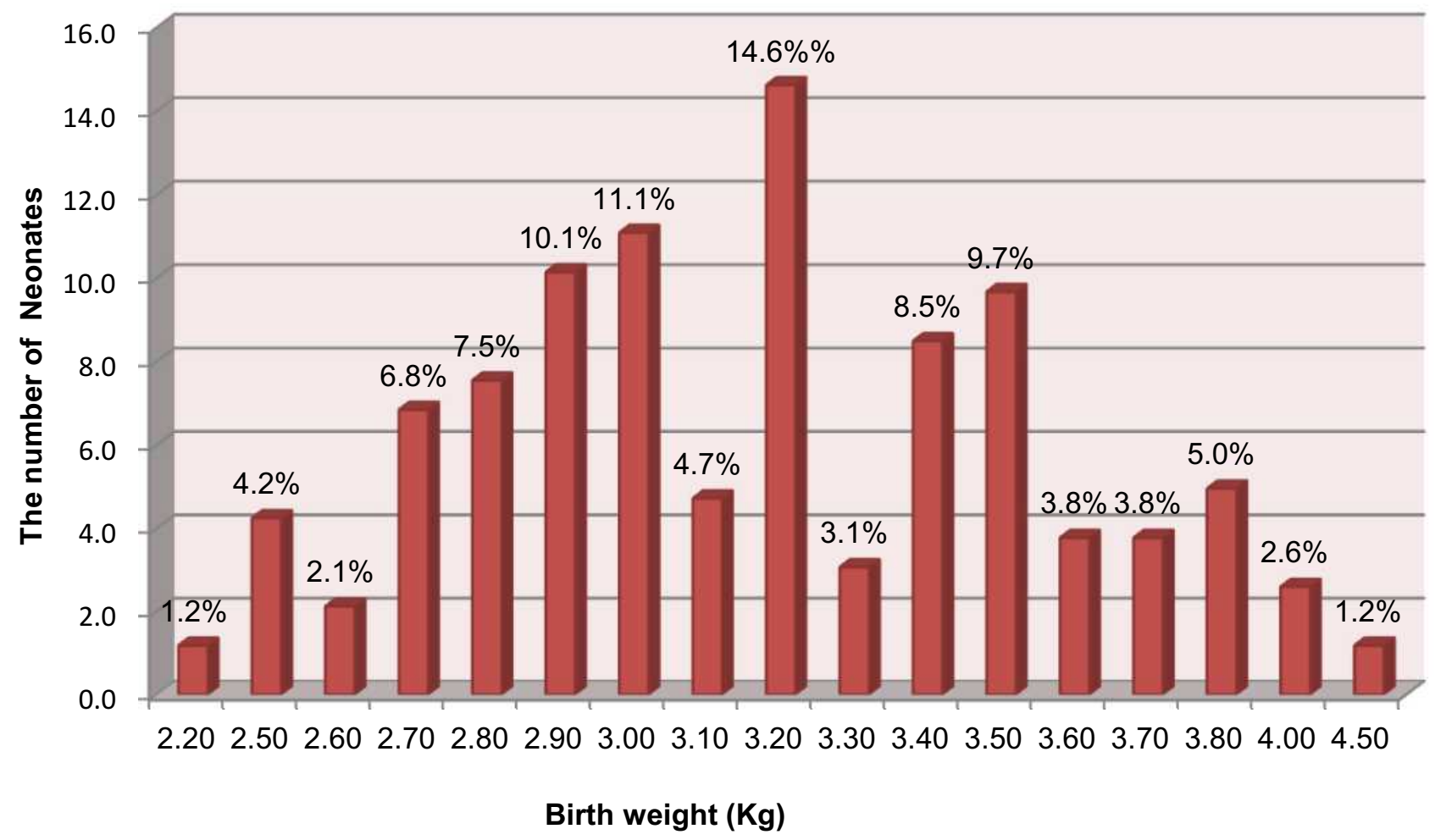

Figure I Break-up of the study sample in each birth weight in Finote Selam Hospital, Ethiopia.

parameters such as foot length (FL), hand length (HL), midupper arm circumferences (MUAC), crown-heel length (CHL), intermammary distance (IMD), umbilical-nipple distance (UND) and head circumference (HC) had a positive statistically significant correlation with birth weight $(p<0.05)$. The correlation coefficient $(R)$ value ranged from 0.336 to 0.474 . The highest correlation was observed on MUAC ( $r=0.474)$ followed by FL $(r=0.461)$. Conversely, a weak correlation was observed on UND $(r=0.336)$.

To predict or estimate birth weight from neonatal anthropometric measurements, simple and multiple linear regression analyses were carried out. It was observed that the maximum significant correlation $(r=0.661, p=0.000 ; p<0.05)$ was obtained when all neonatal anatomical parameters were

Table 2 Prediction of Birth Weight from Neonatal Anthropometric Parameters in Finote Selam Hospital, Ethiopia

\begin{tabular}{|l|l|l|l|l|l|l|}
\hline Parameters & $R$ & $R^{2}$ & Adjusted $\boldsymbol{R}^{2}$ & SEE & Regression Equations of BW (kg) & Sig. \\
\hline MUAC $(\mathrm{cm})$ & 0.474 & 0.225 & 0.223 & 0.358 & $0.117+[0.284 \times \mathrm{MUAC}]$ & 0.000 \\
\hline FL $(\mathrm{cm})$ & $0.46 \mathrm{I}$ & 0.213 & 0.211 & $0.36 \mathrm{I}$ & $1.137+[0.254 \times \mathrm{FL}]$ \\
\hline CHL $(\mathrm{cm})$ & 0.423 & 0.179 & 0.177 & 0.369 & $0.485+[0.054 \times \mathrm{CHL}]$ \\
\hline HC $(\mathrm{cm})$ & 0.371 & 0.137 & 0.135 & 0.378 & $0.141+[0.083 \times \mathrm{HC}]$ \\
\hline IMD $(\mathrm{cm})$ & 0.364 & 0.133 & 0.131 & 0.379 & $1.587+[0.179 \times 1 \mathrm{MD}]$ \\
\hline UND $(\mathrm{cm})$ & 0.336 & 0.113 & 0.111 & 0.383 & $1.506+[0.166 \times \mathrm{UND}]$ \\
\hline HL $(\mathrm{cm})$ & 0.360 & 0.129 & 0.127 & 0.380 & $1.690+[0.206 \times \mathrm{HL}]$ \\
\hline MUAC, HL, FL and CHL & 0.661 & 0.437 & 0.428 & 0.307 & $-2.489+[0.192 \times \mathrm{MUAC}]+[0.078 \times \mathrm{HL}]+[0.11 \times \mathrm{FL}]+[0.036 \times \mathrm{CHL}]$ & \\
\hline
\end{tabular}

Notes: $R$, correlation coefficient; $R^{2}$, coefficient of determination.

Abbreviations: BW, birth weight; CHL, crown-heel length; cm, centimeter; FL, foot length; HC, head circumference; HL, hand length; IMD, intermammary distance; Sig., significance $(P<0.05)$; SEE, standard error of estimate; UND, umbilical-nipple distance; kg, kilogram; MUAC, mid-upper arm circumference. 
A

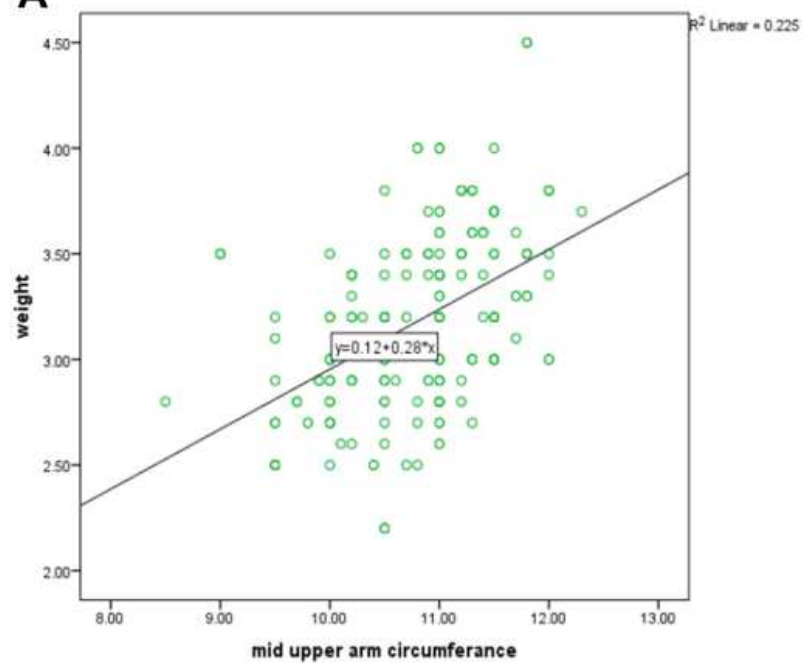

B

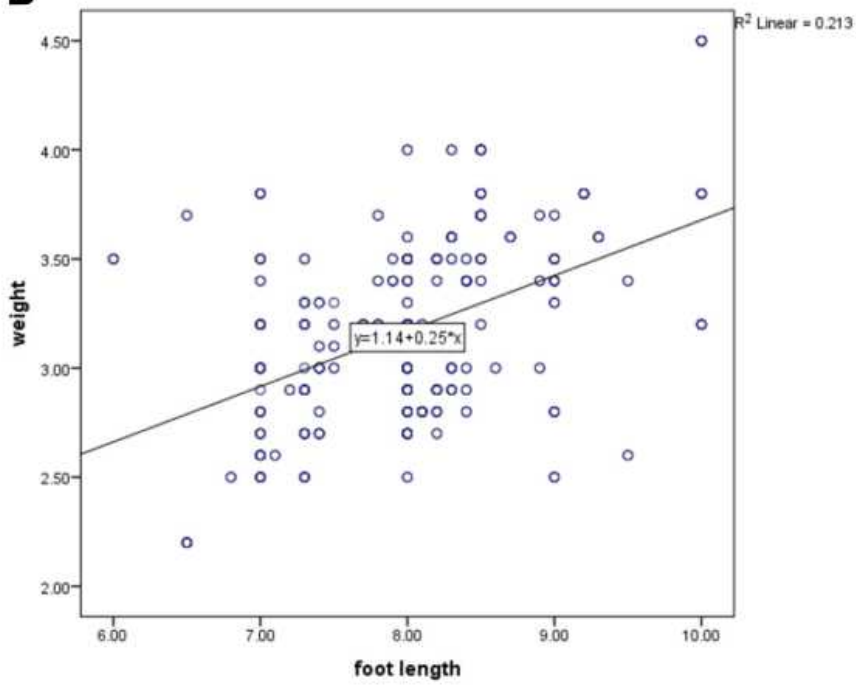

Figure 2 Scatter plot revealing the relationship between birth weight and mid-upper arm circumference (A) and foot length (B).

entered in multiple linear regression analysis. On multiple linear regression analysis, MUAC, HL, FL and CHL had significant correlation with birth weight $(p<0.05)$, whereas $\mathrm{HC}$, IMD and UND had no significant correlation $(p>0.05)$. Therefore, the most important significant correlation was obtained from combined neonatal anthropometric parameters like MUAC, HL, FL and CHL $(r=0.661, p=0.000 ; p<0.05)$ followed by individual parameters (MUAC $=0.474, p=0.000$; $p<0.05)$. Therefore, the best regression model to predict birth weight $(\mathrm{kg})$ of neonate was $=-2.489+[0.192 \times$ MUAC $]$ $+[0.078 \times \mathrm{HL}]+[0.11 \times \mathrm{FL}]+[0.036 \times \mathrm{CHL}] \quad(r=0.661, p=0.000 ;$ $p<0.05)$ followed by birth weight $(\mathrm{kg})=0.117$ $+[0.284 \times$ MUAC $](r=0.474, p=0.000 ; p<0.05)$ (Table 2$)$.

Regarding the scatter plot of the selective neonatal parameters with birth weight, the fit line at the total revealed that the relationship between birth weight with their respective mid-upper arm circumferences and dispersion from the line at $R^{2}$ linear $=0.225$ (Figure $2 \mathrm{~A}$ ). The fit line at the total indicating the relation between birth weight and their respective foot length and the dispersion from the line at $R^{2}$ linear $=0.213$ (Figure 2B).

\section{Regression Model Predictive Accuracy Measurements}

Concerning the predictive capacity of the regression model, the combined parameters (model 8) had better predictive capability followed by the MUAC individual parameter (model 1), which had a mean absolute error (MAE) of 0.260 and 0.286 , respectively. In addition, the mean absolute percentage error revealed that the combined parameters (model 8) had a better predictor followed by the MUAC individual parameter (model 1), each being 8.283 and 9.143 , respectively (Table 3 ).

\section{Discussion}

This prospective cross-sectional study was conducted in Finote Selam hospital. It was intended to predict or estimate birth weight from neonatal anthropometric measurements. The birth weight scale has been and is still an

Table 3 Predictive Accuracy Measure of the Regression Model in Finote Selam Hospital, Ethiopia

\begin{tabular}{|l|l|l|l|l|}
\hline No. & Models & MAE & MAPE & Sig. \\
\hline I. & $0.117+[0.284 \times \mathrm{MUAC}]$ & 0.286 & 9.143 & 0.000 \\
\hline 2. & $1.137+[0.254 \times \mathrm{FL}]$ & 0.289 & 9.266 & 0.000 \\
\hline 3. & $0.485+[0.054 \times \mathrm{CHL}]$ & 0.308 & 9.880 & 0.000 \\
\hline 4. & $0.141+[0.083 \times \mathrm{HC}]$ & 0.311 & 9.910 & 0.000 \\
\hline 5. & $1.587+[0.179 \times 1 \mathrm{MD}]$ & 0.299 & 9.513 & 0.000 \\
\hline 6. & $1.506+[0.166 \times \mathrm{UND}]$ & 0.313 & 10.047 & 0.000 \\
\hline 7. & $1.690+[0.206 \times \mathrm{HL}]$ & 0.312 & 9.969 & 0.000 \\
\hline 8. & $\begin{array}{l}-2.489+[0.192 \times \mathrm{MUAC}] \\
+[0.078 \times \mathrm{HL}]+[0.111 \times \mathrm{FL}]\end{array}$ & 0.260 & 8.283 & 0.000 \\
$+[0.036 \times \mathrm{CHL}]$ & & & \\
\hline
\end{tabular}

Abbreviations: BW, birth weight; $\mathrm{CHL}$, crown-heel length; FL, foot length; $\mathrm{HC}$, head circumference; $\mathrm{HL}$, hand length; IMD, intermammary distance; Sig., significance $(P<0.05)$; UND, umbilical-nipple distance; MUAC, mid-upper arm circumference; MAE, mean absolute error; MAPE, mean average percentage error. 
important screening tool for identifying newborns with LBW. However, in a developing country, there is inaccessibility or inaccurate weighing scales and a higher incidence of home deliveries so that measuring weight and identifying neonates with LBW is difficult. ${ }^{19}$ This indicates a need for other procedures to evaluate the birth weight of newborns. A measuring tape is easily handy and can be used by community health workers like health extension workers in Ethiopia when they are informed of delivery in a community in their working area.

The current study revealed that birth weight had a positive significant correlation with different neonatal anthropometric parameters at birth. The study was supported by different studies. ${ }^{12,20-22}$ The present investigation aimed to show the relation between birth weight and various neonatal anthropometric measurements. However, most of the previous investigators carried out few neonatal anthropometric parameters. The current investigation will add new knowledge on the association between birth weight and various neonatal anthropometric parameters.

In the present study, out of the various neonatal anthropometric parameters, the best significant correlation was observed for MUAC followed by FL, each accounting for $r=0.474$ and $r=0.461$, respectively. This revealed that MUAC and FL anthropometric measurements were the best parameters to identify low birth weight in resourcelimited countries. The finding was in agreement with a study carried out in India by Rustagi et al, which revealed that MUAC had the highest correlation with birth weight $(r=0.664)$ as compared to other neonatal anthropometric measurements. ${ }^{23}$ It was also supported by a study conducted in Bangladesh by Das et al, who observed that MUAC $(r=0.956)$ was the best parameter to screen for low birth weight babies. ${ }^{24}$ However, there is a difference in the strength of association compared to the current study. This discrepancy might be due to the fact that the current study sample size was relatively smaller than the study carried out in Bangladesh. And also, it might be due to the use of many neonatal parameters to predict neonatal birth weight in the current study as compared to the study from Bangladesh, and socioeconomic difference as well.

Furthermore, the current study findings differed from those from a study carried out in India by Sajjadian et al, from which it was evident that the maximum correlation with birth weight was observed on chest circumference $(r=0.74)$ followed by the mid-arm circumference $(r=0.70) .{ }^{25}$ Besides, Otupiri et al in Ghana indicated that chest circumference $(r=0.69)$ followed by MUAC $(r=0.68)$ had the highest correlation with birth weight, so they were the best parameters to identify low birth weight. ${ }^{26}$ This inconsistency might be due to the fact that the chest circumference was not included among the indicator parameters for estimation of BW in this study since timing the end of expiration to measure the chest circumference was challenging. This could have implications for use of these measurements by community health workers. ${ }^{20}$

This study did not evaluate the prediction capacity of neonatal anthropometric measurements for the identification of LBW beyond one day after birth. However, a study conducted in Tanzania by Marchant et al revealed that the foot length had a good predictive capacity for the identification of LBW up to day 5 after birth. ${ }^{27}$ Another study conducted in Uganda by Wabwire-Mangen et al also stated that $\mathrm{HC}$ can be measured in the first 2 weeks of life and used to infer the measurement on the day of birth. ${ }^{28}$ Therefore, our finding could be crucial because community health workers, which are called health extension workers in Ethiopia, may not visit the newborn on the first day of life.

This study formulated different regression equations from different neonatal anthropometric parameters to predict or estimate birth weight in kilogram $(\mathrm{kg})$ and found that the best correlation was obtained in combination of MUAC, HL, FL and CHL $(r=0.661)$ and formulated as birth weight in $\mathrm{kg}=$ $-2.489+[0.192 \times \mathrm{MUAC}(\mathrm{cm})]+[0.078 \times \mathrm{HL}(\mathrm{cm})]+[0.111 \times \mathrm{FL}$ $(\mathrm{cm})]+[0.036 \times \mathrm{CHL}(\mathrm{cm})]$, followed by a simple linear regression equation on individual anthropometric parameters. Amongst the individual parameters, the best correlation was obtained from MUAC ( $r=0.474)$ followed by FL $(r=0.461)$ so that the regression equation to predict birth weight was formulated as birth weight in $\mathrm{kg}=0.117+[0.284 \times \operatorname{MUAC}(\mathrm{cm})]$ and birth weight in $\mathrm{kg}=1.137+[0.254 \times \mathrm{FL}(\mathrm{cm})]$, respectively. To our knowledge, no research has formulated a regression equation using a combination of neonatal anthropometric measurements. Thus, the finding will improve the identification of low birth weight in developing countries including Ethiopia. The formulated equations are simple, quick and cost-effective and could be used by community health workers so that they can identify low birth weight neonates and then refer them to the higher health institution for further management.

\section{Limitations of the Study}

The measurements were done by trained health workers, but the tool will be used at the community level by 
primary health workers and their skills are likely to be different. Our equation using multiple variables may be a source of error in clinical use so that to reduce error training may be needed.

\section{Conclusion}

In conclusion, birth weight had a positive significant correlation with all neonatal anthropometric measurements such as CHL, HC, HL, MUAC, FL, IMD and UND. The best correlation was found by a combination of MUAC, HL, FL and CHL, followed by MUAC individual parameters.

The best predictive model for birth weight is obtained by the combined parameters MUAC, HL, FL and CHL. These simple and multiple linear predictive models are simple, cost-effective and quick. Therefore, by using an ordinary measuring tape, low birth weight can be identified by community-level health workers, and then they can refer LBW neonates to the higher health institution for further management.

\section{Data Sharing Statement}

The datasets used and/or analyzed during the current study are available from the corresponding author on reasonable request.

\section{Ethical Approval and Consent to Participate}

Before data collection, ethical clearance was obtained from the Department of Research Ethics Review Committee (DRERC) of Wollo University, College of Medicine and Health Science, Department of Preclerkship. A supportive letter was sent to Finote Selam Hospital, and consent was gained from the hospital director to conduct the study. The purpose of the study was explained to the director of Finote Selam Hospital and midwifery staff. Additionally, all participants' parents/ legal guardians were informed about the purpose and confidentiality issues related to the study. Participation was voluntary. Written informed consent was obtained from each participant's parent/guardians who could read and write, whereas verbal informed consent was obtained from the participant's parent/legal guardians who could not read and write, and the verbally informed consent process was approved by the DRERC of Wollo University. Finally, data were collected and client information was maintained. Lastly, the authors confirm that this study was conducted in accordance with the Declaration of Helsinki.

\section{Acknowledgment}

We acknowledge the contributions of study participants and staff of Finote Selam Hospital.

\section{Disclosure}

The authors declare that there is no conflict of interest regarding the publication of this paper.

\section{References}

1. Ahmad OB, Lopez AD, Inoue M. The decline in child mortality: a reappraisal. Bull World Health Organ. 2000;78:1175-1191.

2. Wang H, Liddell CA, Coates MM, et al. Global, regional, and national levels of neonatal, infant, and under-5 mortality during 1990-2013: a systematic analysis for the Global Burden of Disease Study 2013. Lancet. 2014;384(9947):957-979. doi:10.1016/S01406736(14)60497-9

3. Black RE, Levin C, Walker N, et al. Reproductive, maternal, newborn, and child health: key messages from disease control priorities 3rd edition. Lancet. 2016;388(10061):2811-2824. doi:10.1016/ S0140-6736(16)00738-8

4. McGuire SF. Understanding the Implications of Birth Weight. Nurs Women's Health. 2017;21(1):45-49. doi:10.1016/j.nwh.2016.12.005

5. WHO. Handbook for Guideline Development. Geneva; 2008-2011

6. Dhar B, Mowlah G, Nahar S, Islam N. Birth-weight status of newborns and its relationship with other anthropometric parameters in a public maternity hospital in Dhaka, Bangladesh. J Health Popul Nutr. 2002;36-41.

7. Yadav DK, Chaudhary U, Shrestha N. Risk factors associated with low birth weight. J Nepal Health Res Counc. 2011;9:159-164.

8. World Health Organization. Guidelines on optimal feeding of low birth-weight infants in low-and middle-income countries. World Health Organization; 2011.

9. WHO. Handbook for Guideline Development. Geneva:WHO; 2008-2011.

10. Viengsakhone L, Yoshida Y, Harun-Or-Rashid MD, Sakamoto J. Factors affecting low birth weight at four central hospitals in vientiane, Lao PDR. Nagoya J Med Sci. 2010;72(1-2):51-58.

11. ACC U. Low Birth weight: report from a Meeting in Dhaka, Bangladesh on 14-17 June 1999. Nutrition Policy Paper, No. 18; 2000.

12. Hadush MY, Berhe AH, Medhanyie AA. Foot length, chest and head circumference measurements in detection of low birth weight neonates in Mekelle, Ethiopia: a hospital based cross sectional study. BMC Pediatr. 2017;17(1):1-8. doi:10.1186/s12887-017-0866-0

13. Jitta J, Kyaddondo D. Situation analysis of newborn health in Uganda. The Republic of Uganda:Kampala Uganda: Ministry of Health; 2008.

14. Tiruneh C. Estimation of gestational age using neonatal anatomical anthropometric parameters in Dessie Referral Hospital, Northeast Ethiopia. Risk Manag Healthc Policy. 2020;13:3021. doi:10.2147/ RMHP.S280682

15. Khanapurkar S, Radke A. Estimation of stature from the measurement of foot length, hand length and head length in Maharashtra region. Indian J Basic Appl Med Res. 2012;1(2):77-85.

16. Thawani R, Dewan P, Faridi M, Arora SK, Kumar R. Estimation of gestational age, using neonatal anthropometry: a cross-sectional study in India. J Health Popul Nutr. 2013;31(4):523. doi:10.3329/jhpn. v31i4.20051 
17. Mansur D, Haque M, Sharma K, Mehta D, Shakya R. Use of head circumference as a predictor of height of individual. Kathmandu Univ Med J. 2014;12(2):89-92. doi:10.3126/kumj.v12i2.13651

18. Nemade P, Ambiye M, Nemade A. Regression analysis on stature estimation from cephalic dimensions. Indian J Basic Appl Med Res. $2015 ; 4: 298-312$.

19. WHO. Use of a simple anthropometric measurement to predict birth weight. WHO Collaborative Study of Birth Weight Surrogates. Bull World Health Organ. 1993;71:157-163.

20. Elizabeth NL, Christopher OG, Patrick K. Determining an anthropometric surrogate measure for identifying low birth weight babies in Uganda: a hospital-based cross sectional study. BMC Pediatr. 2013;13(1):1-7. doi:10.1186/1471-2431-13-54

21. Chukwudi NK, Nwokeukwu HI, Adimorah GN. Use of a simple anthropometric measurement to identify low-birth-weight infants in Enugu, Nigeria. Global Pediatric Health. 2018;5:2333794X18788174. doi:10.1177/2333794X18788174

22. Goto E. Meta-analysis: identification of low birth weight by other anthropometric measurements at birth in developing countries. J Epidemiol. 2011;21(5):354-362. doi:10.2188/jea.JE20100182

23. Rustagi N, Prasuna J, Taneja D. Anthropometric surrogates for screening of low birth weight newborns: a community-based study. Asia Pacific J Public Health. 2012;24(2):343-351. doi:10.1177/ 1010539510384717
24. Das JC, Afroze A, Khanam S, Paul N. Mid-arm circumference: an alternative measure for screening low birth weight babies. Bangladesh Med Res Counc Bull. 2005;31(1):1-6.

25. Sajjadian N, Shajari H, Rahimi F, Jahadi R, Barakat MG. Anthropometric measurements at birth as predictor of low birth weight. Health. 2011;3(12):752-756. doi:10.4236/health.2011.312125

26. Otupiri E, Wobil P, Nguah SB, Hindin MJ. Anthropometric measurements: options for identifying low birth weight newborns in Kumasi, Ghana. PLoS One. 2014;9(9):e106712. doi:10.1371/journal. pone.0106712

27. Marchant T, Jaribu J, Penfold S, Tanner M, Schellenberg JA. Measuring newborn foot length to identify small babies in need of extra care: a cross sectional hospital based study with community follow-up in Tanzania. BMC Public Health. 2010;10(1):1-9. doi:10.1186/1471-2458-10-624

28. Wabwire-Mangen F, Kigozi G, Gray RH. Estimation of birth weight and gestational age during the first two weeks of life among home deliveries. Int J Gynaecol Obstet. 2002;79(3):255-257. doi:10.1016/ S0020-7292(02)00249-7

\section{Publish your work in this journal}

Pediatric Health, Medicine and Therapeutics is an international, peerreviewed, open access journal publishing original research, reports, editorials, reviews and commentaries. All aspects of health maintenance, preventative measures and disease treatment interventions are addressed within the journal. Practitioners from all disciplines are invited to submit their work as well as healthcare researchers and patient support groups. The manuscript management system is completely online and includes a very quick and fair peer-review system. Visit http://www.dovepress.com/testimonials.php to read real quotes from published authors. 